\title{
28 Resarach Soure \\ Projections of Cold Air Outbreaks In CMIP6 Earth System Models
}

Erik T. Smith ( $\square$ esmit149@kent.edu )

Kent State University https://orcid.org/0000-0002-8133-0348

Scott Sheridan

Kent State University

\section{Research Article}

Keywords: Cold air outbreaks, extreme cold events, climate modeling, ERA5, CMIP6, shared socioeconomic pathways

Posted Date: July 27th, 2021

DOl: https://doi.org/10.21203/rs.3.rs-697105/v1

License: (1) This work is licensed under a Creative Commons Attribution 4.0 International License. Read Full License

Version of Record: A version of this preprint was published at Climatic Change on November 1st, 2021. See the published version at https://doi.org/10.1007/s10584-021-03259-x. 


\section{Abstract}

Historical and future simulated temperature data from five climate models in the Coupled Model Intercomparing Project Phase 6 (CMIP6) are used to understand how climate change might alter cold air outbreaks (CAOs) in the future. Three different Shared Socioeconomic Pathways (SSPs), SSP $1-2.6$, SSP $2-4.5$, and SSP $5-8.5$ are examined to identify potential fluctuations in CAOs across the globe between 2015 and 2054. Though CAOs may remain persistent or even increase in some regions through 2040, all five climate models show CAOs disappearing by 2054 based on current climate percentiles. Climate models were able to accurately simulate the spatial distribution and trends of historical CAOs, but there were large errors in the simulated interannual frequency of CAOs in the North Atlantic and North Pacific. Fluctuations in complex processes, such as Atlantic Meridional Overturning Circulation, may be contributing to each model's inability to simulate historical CAOs in these regions.

\section{Plain Language Summary}

Cold air outbreaks (CAOs) are extreme events that can have large, negative impacts on society. Because of these impacts it is important to understand how climate change might alter CAOs in the future. Three future scenarios from five different climate models are examined to see where CAOs might change the most between 2015 and 2054. While changes in CAOs may be small for some regions through 2040, all the climate models show CAOs disappearing by 2054. Where the climate models did a good job simulating historical CAOs, like in North America, we have confidence that future projections are relatively accurate. Where the models did poorly at simulating historical CAOs, like the North Atlantic and North Pacific, we have less confidence in future projections. More work needs to be done to understand the complex processes that lead to these errors.

\section{Introduction}

Cold Air Outbreaks (CAO) are extreme events that can negatively impact multiple facets of society. Though infrequent, extreme weather events cause significantly more damage than non-extreme events (Bell et al., 2018; Schewe et al., 2019). CAOs have been shown to increase the risk of human mortality (Smith \& Sheridan, 2019), cause agricultural production losses (Lesk et al., 2016), and cause widespread power outages from increased energy consumption (Y. Kim \& Lee, 2019; Klinger et al., 2014). Because of the large impacts on society, accurately projecting how extremes like CAOs will change under future warming scenarios is a critical step in developing a more resilient society.

Climate models, which are derived from substantiated physical principles of the earth system process, are the best tool we have for predicting changes in CAOs (Flato, 2011; Raäisaänen, 2007; Randall et al., 2007). Climate models use dynamical and statistical calculations to represent earth's climate system and propagate the current atmospheric state forward in time (Collins et al., 2013; Randall et al., 2007; Richardson, 2007). The accuracy of future projections depends on the data used to initialize the climate model, thus small inaccuracies are exacerbated through time, leading to increased error with longer range 
projections (Polkova et al., 2019). With no way to evaluate future projections from climate models, the ability of a climate model to represent future climates must be assessed by comparing simulations of historical climates with observations or reanalysis datasets (Edwards, 2011). While observations are point based, atmospheric reanalysis datasets are a gridded historical dataset of global atmospheric circulation that use weather models to reanalyze assimilated observations over much shorter timescales than climate models (Dee et al., 2011). Because reanalysis datasets are gridded, they provide an easier comparison with climate model output. They also allow comparisons in data sparse regions like the Arctic and across oceans.

The Coupled Model Intercomparison Project (CMIP) has become the foundation for numerous climate assessments (IPCC, 2013). CMIP uses multiple climate models from modelling centers around the world to better understand past climates and future changes (Eyring et al., 2016). Phase 6 of CMIP (CMIP6) aims to make the multi-model output publicly available and more user-friendly by standardizing the format. New to CMIP6 is the Scenario Model Intercomparison Project (ScenarioMIP), which integrates inputs from both the climate science and integrated assessment modelling communities to create future modeling scenarios (Eyring et al., 2016; O’Neill et al., 2016; Tebaldi et al., 2020). These new scenarios, called Shared Socioeconomic Pathways (SSPs), combine pathways of future radiative forcing with alternative pathways of socioeconomic development to characterize the range of uncertainty in climate adaptation and mitigation efforts (O'Neill et al., 2014). Global energy systems, which are the leading contributor to carbon emissions, are particularly vulnerable to climate changes, yet developments are limited by political and social acceptance (Bauer et al., 2017). The addition of SSPs in CMIP6 is an essential step in determining how carbon emissions may fluctuate with changes in global energy systems (Davis et al., 2018; X. Liu et al., 2019).

Though we cannot be certain if modeled changes in CAOs will be realized, we can get a good idea if models are on the right track based on how models simulate historical climates (Jeuken et al., 1996; HanLi Liu et al., 2018). While many studies have examined projected changes in air temperature (Almazroui et al., 2020; Friedrich et al., 2016; Jones et al., 2013; Kumar et al., 2013; Tokarska et al., 2020), only a few studies have explicitly investigated changes in CAOs (Kolstad \& Bracegirdle, 2008; Vavrus et al., 2006). These studies showed that while CAOs have decreased across much of the globe in recent decades, there was also an increase in some regions (J. L. Cohen et al., 2012; Smith \& Sheridan, 2020). While this increase in CAOs may continue over the next few decades for some regions (Kolstad \& Bracegirdle, 2008; Vavrus et al., 2006), most places will likely experience a large decrease in CAOs throughout the $21^{\text {st }}$ century (Ayarzagüena \& Screen, 2016; Vavrus et al., 2006; Zahn \& von Storch, 2010).

This study uses climate model output from CMIP6 to better understand how the frequency of CAOs may change across the globe between 2015 and 2054. Historical climate model simulations from $1979-$ 2014 are examined to determine how well five different climate models reproduce the spatial and temporal distribution of CAOs. Three different SSPs are examined to determine a range of potential fluctuations in CAOs between 2015 and 2054. These findings have the potential to mitigate damages and future energy system vulnerabilities by quantifying regional changes in CAOs. 


\section{Data And Methods}

The global CAO dataset from Smith (2020) and CAO regions created by Smith \& Sheridan (2020) were used to compare historical CMIP6 CAO simulations with actual CAOs. This CAO dataset was created from daily mean T2m from the ERA5 reanalysis dataset from the European Center for Medium-Range Weather Forecasts (ECMWF; from https://cds.climate.copernicus.eu/cdsapp\#!/home; Copernicus Climate Change Service) at a $1^{\circ}$ spatial resolution from 1979 - 2014. CAOs were quantified using a set of criteria concerning intensity, duration, and spatial extent of the extreme cold airmass, where the daily mean T2m was required to be below the $2.5^{\text {th }}$ percentile, based on the $1981-2010$ climate normal period, for at least 5 consecutive days for a contiguous area of at least 1,000,000 km² (Smith \& Sheridan, 2020). The use of a percentile threshold limits the impact of the skewness of the data on the spatial distribution of CAOs. Future simulations of CAOs use the percentile thresholds from the $1981-2010$ climate normal period. CAO regions were used to simplify the analysis from thousands of grid points to 10 regions with similar CAO characteristics and CAO trends (Smith \& Sheridan, 2020).

As CMIP6 is still in progress, output from all models is not yet available. Historical and projected daily mean two-meter temperature (T2m) data were acquired from the same variant, r1i1p1f1, of five Earth System Models: CESM2, CESM2-WACCM, MPI-ESM1-2-HR, MRI-ESM2-0, and CanESM5 (Danabasoglu et al., 2020; Gutjahr et al. 2019; Swart et al., 2019; Yukimoto et al., 2019). Three different shared socioeconomic pathways (SSPS), SSP1, SSP2, and SSP5 are integrated with three different forcing pathways stabilizing at $2.6 \mathrm{~W} \mathrm{~m}^{-2}, 4.5 \mathrm{~W} \mathrm{~m}^{-2}, 8.5 \mathrm{~W} \mathrm{~m}^{-2}$ to create three scenarios of future climate and societal change (O'Neill et al., 2014). From each of the five climate models, these integrated scenarios, denoted as SSP1-2.6 (SSP126), SSP2-4.5 (SSP245), and SSP5-8.5 (SSP585), were used to explore a range of potential changes in CAOs across the globe. Data from the CMIP6 archive is publicly available from the Earth System Grid Federation (ESGF; https://esgf-node.IInl.gov/search/cmip6/). To maintain consistency with the time period used in Smith \& Sheridan (2020) and because CMIP6 historical output ends in 2014, historical T2m was acquired for 1979 - 2014 while projected T2m was acquired for 2015 2054. These five models allow for an in-depth analysis of both historical climate simulations and future projections of CAOs. The $\mathrm{T} 2 \mathrm{~m}$ for each climate model was regridded to a $1^{\circ} \times 1^{\circ}$ resolution using a bilinear interpolation to match the resolution of the ERA5 derived CAO dataset. Because bilinear interpolation creates a quadratic sample by linearly interpolating the data in two different directions, it is generally better at rescaling data than a linear interpolation (Wang et al., 2016).

Trends in the annual number of CAO days, derived from historical T2m climate model output, were calculated and compared with the observed trends. This is used to determine if each climate model is able to accurately simulates spatial and temporal fluctuations in CAOs. As outlined by Smith \& Sheridan (2020), trends for the Southern Hemisphere (SH) were calculated for 36 winter seasons (January 1 December 31) while trends in the Northern Hemisphere (NH) were calculated for 35 winter seasons (July 1 - June 30). Due to the limited sample size (35 in NH and 36 in SH), a Theil-Sen slope estimation was calculated from 1000 bootstrapped samples and statistical significance determined from the confidence 
intervals produced from the bootstrapped samples. Moreover, a false detection rate was used to limit the false significance of the spatiotemporal relationships of the gridded data (Wilks, 2016).

Because of inherent errors in climate model simulations, various statistical or dynamical techniques are often used to reduce biases (Maraun, 2016). However, many of these methods can mask the uncertainty in projections by altering simulations without providing a physical mechanism to explain why the corrections reduce the bias (Ehret et al., 2012). Climate projections based on an ensemble of several models increase the reliability and consistency of independent projections while maintaining transparency of systematic model errors (Tebaldi et al., 2020; Yun et al., 2003). For this reason, the mean of the five climate models is used as an ensemble for both historical simulations and each SSP to provide the least biased estimate of future changes in CAOs.

\section{Results}

\subsection{Historical Simulations of CAOs}

From 1979 - 2014, CAOs occurred most frequently across North America and Eurasia. Each of the five climate models were able to reproduce the same general spatial distribution of CAOs as observed with the ERA5, however, each model had a warm bias in the North Atlantic, with the CESM2, WACCM, and MPI having the largest bias (Figure 1). This bias can likely be attributed to how each climate model handles the Atlantic Meridional Overturning Circulation (AMOC; Gent, 2018) or air-sea interactions from fluctuations in Arctic sea ice (Kolstad \& Bracegirdle, 2008). Climate model simulations have been shown to underestimate the weakening of the AMOC (Hu et al., 2013; Meehl et al., 2020), which favors more CAOs in the North Atlantic. This may account for the simulation of too few CAOs early in the historical period (R4; Figure A1). The CanESM5 has a cold bias across the western United States and like the MPI, a warm bias across the oceans which is largest in the Southern Pacific. Conversely, the MRI has a large cold bias in the Northern Hemisphere (NH), particularly across the Arctic.

Spatial and temporal similarity were calculated to determine which climate model most accurately simulated the spatial distribution and annual frequency of CAOs for each region (Table 2). While each model was able to simulate the general spatial distribution of CAOs, some regions were better modeled than others (SS; Table 2). Moreover, there were large discrepancies between the time series of mean regional annual CAO days simulated by the climate models and the mean regional annual CAO days from the ERA5 (mean absolute error; MAE; Table2). The CESM2 and MPI had a large warm bias across multiple regions and the largest total error in the SS of annual CAO days. The WACCM (full name: CESM2WACCM), an extension of CESM2 that models the entire atmosphere (Liu et al., 2010), had less overall bias in SS than the CESM2, followed by theCanESM5 and the MRI. The MRI had the lowest MAE with North America (R1 and R2) while the MPI and WACCM had the lowest MAE in Eurasia. In nearly every region, the model ensemble reduces the errors in spatial similarity (SS) and temporal similarity (MAE).

Table 1: Climate model spatial (SS) and temporal (MAE) historical simulation accuracy (1979-2014).

Spatial similarity (SS) - difference between regional mean annual CAO days and the observed annual 
mean CAO days from the ERA5. The mean absolute error (MAE) is calculated for the annual number of CAO days per region in the historical climate model simulations and the observed (ERA5). Red/blue SS shows where the mean annual CAO days is less than/more than the ERA5. A red/yellow MAE shows where the MAE is large/small. Color intensity of the MAE is relative to the region. Total error is the sum of the absolute values of each column.

\begin{tabular}{|llllllllllllll|}
\hline & \multicolumn{2}{l}{ CESM2 } & \multicolumn{2}{l}{ WACCM } & MPI & \multicolumn{3}{c}{ MRI } & \multicolumn{3}{c|}{ CanESM5 } & \multicolumn{2}{c|}{ Ensemble } \\
\hline Region & SS & MAE & SS & MAE & SS & MAE & SS & MAE & SS & MAE & SS & MAE \\
\hline R1 & -1.0 & 3.7 & 0.2 & 4.1 & -0.5 & 3.9 & -0.2 & 3.2 & 0.2 & 3.9 & -0.3 & 2.8 \\
\hline R2 & -0.2 & 5.2 & -0.2 & 6.0 & 0.0 & 6.3 & 0.2 & 4.6 & 0.0 & 4.7 & 0.0 & 4.2 \\
\hline R3 & 0.3 & 5.4 & 0.1 & 5.5 & -1.2 & 5.0 & 0.2 & 5.3 & -0.4 & 5.7 & -0.2 & 4.3 \\
\hline R4 & -1.7 & 4.3 & -1.6 & 5.0 & -1.9 & 5.0 & -1.0 & 5.6 & -1.0 & 4.1 & -1.4 & 4.2 \\
\hline R5 & -0.6 & 5.5 & 0.4 & 4.9 & 0.1 & 5.1 & 0.9 & 5.6 & 0.8 & 6.7 & 0.3 & 4.4 \\
\hline R6 & 0.2 & 5.4 & 0.0 & 4.7 & -0.3 & 4.5 & 0.5 & 5.8 & -0.1 & 5.5 & 0.1 & 3.9 \\
\hline R7 & -0.8 & 4.6 & -0.4 & 4.8 & -0.9 & 4.0 & -1.0 & 3.3 & -0.5 & 3.2 & -0.7 & 3.3 \\
\hline R8 & 0.0 & 3.6 & 0.6 & 3.6 & 0.6 & 3.4 & -0.3 & 2.9 & 0.8 & 3.9 & 0.3 & 2.9 \\
\hline R9 & -1.0 & 2.6 & -0.2 & 2.6 & 0.3 & 2.5 & 0.6 & 3.3 & -0.3 & 2.2 & -0.1 & 2.2 \\
\hline R10 & -0.1 & 1.5 & 0.2 & 2.0 & -0.6 & 1.6 & 0.1 & 1.5 & 0.3 & 1.7 & 0.0 & 1.3 \\
\hline Total Error & 5.7 & 42.0 & 4.0 & 43.3 & 6.5 & 41.2 & 4.9 & 41.2 & 4.4 & 41.8 & 3.5 & 33.6 \\
\hline
\end{tabular}

While there were large discrepancies between the observed and simulated annual number of CAO days (MAE), the spatial distribution of the simulated trends matched the observed trends relatively well (Figure 2). Each model shows the largest decreases in annual CAO days across Northern Hemispheric landmasses. The MPI had the smallest historical trends because the simulation produced too few CAOs early in the historical period and too many late in the period for most places. On the other hand, the MRI has a large negative trend because it produced too many CAOs in the Arctic and western Eurasia early in the historical period. Similar to the observed trends from the ERA5, both the MPI and CESM2 had a neutral to positive trend in CAO days in Eurasia. However, the MPI more accurately replicated the location of this positive trend than the CESM2. Like the ERA5, very few simulated trends in the SH were statistically significant, though the MRI and CanESM5 most accurately simulated the positive trend in CAOs across parts of the Southern Ocean.

\subsection{Future Projections of CAOs}

Similar to (Vavrus et al., 2006), CAOs are expected to continue decreasing across most of the globe over the next few decades. Compared to the historical period, the ensemble of each SSP shows the mean 
annual number of CAO days between 2015 and 2054 will decrease between 50\% and 100\% in most locations (Figure 3). The largest decrease in annual CAO days is in North America and Europe where CAOs have historically occurred most frequently. The CESM2, WACCM, and MRI show a large increase in CAOs across the North Atlantic, consistent with previous studies that have shown a continued weakening of the AMOC in climate model projections (Figure A2; Meehl et al., 2020; Zhang et al., 2019). The MPI and MRI also maintain a relatively large number of mean annual CAO days across North America in all three SSPs. While there are generally fewer annual CAO days with SSP245 and SSP585 than in SSP126, SSP245 and SSP585 do not necessarily result in a larger systematic decrease in CAOs. In the MPI model, more CAOs occur in the Southern Atlantic with SSP245 than SSP126. In the CESM2 model, more CAOs occur in the North Atlantic (R4) from SSP245 than SSP126. SSP585 in the MPI, WACCM, and CESM2 also favor more CAOs in Eurasia (R5 and R6) than in SSP245. Moreover, the WACCM SSP245 simulation shows more CAOs in South America (R9) under than the SSP126 simulation.

Climate models simulate the spatial distribution and trends of CAOs well but are unable to accurately model interannual variability. Though a perfect match is not expected, the large discrepancies between historically simulated and observed annual CAO days indicate the models may be simulating the correct trends for the wrong reasons (Luca et al., 2020). These inaccurate representations of historical climate variability in the models can exacerbate errors in future projections of CAOs (Maraun, 2016). As shown with the historical simulations, an ensemble can be used to reduce the magnitude of individual model error, thus an ensemble is also used for each SSP to better estimate changes in CAOs in each region between 2015 and 2054 (Figure 4).

When compared with the observed annual number of CAO days for each region, the ensemble matches the annual variations and trends well (Figure 4). Only R4 and R5 have particularly poor historical simulations. Climate models have been shown to underestimate variability in R4 (W. M. Kim et al., 2018), which may explain why historical simulations simulated too few CAOs early in the historical period. The complex interaction between and amplified Arctic and surface temperatures in Siberia, which is poorly represented in climate models, may account for much of the discrepancy between annual CAO days simulated in R5 (Cohen et al., 2018; Labe et al., 2020).

Future simulations show a consistent decrease in annual CAO days for most regions with several exceptions. All three SSPs simulate a large increase in annual CAO days between 2030 and 2050 in R4. Though historical simulations for R4 where poor, sea ice melt and a weakening of the AMOC supports the notion that the North Atlantic may be a region of large variability in coming decades. In R1 and R2, future simulations show a slight increase in annual CAO days through 2025 and remaining persistent through 2035 before decreasing to approximately zero annual CAO days by 2054. In R3 (Alaska), historical simulations overestimate the annual number of CAO days early in the historical period and underestimate the annual number of $\mathrm{CAO}$ days late in the period which results in an overly negative trend. This suggests the models may be misrepresenting variability in the North Pacific, thus the steady decline in annual CAO days in R3, at least in the near-term, may be off-base. Like R3, historical simulations also underestimated the number of CAO days in R6 (Europe) between 2005 and 2015. Since winter extremes in Europe are 
heavily reliant on North Atlantic circulation (D. M. Smith et al., 2020), a misrepresentation of variability in the North Atlantic may have caused the discrepancies in observed and simulated CAO days in R6. In South America, annual CAO days remain consistent through 2035 in all SSPs before declining to approximately zero annual CAO days in all but SSP126. Across southern Africa, the already infrequent CAO days are shown to steadily decline to approximately zero annual CAO days by 2035 .

\section{Conclusion}

CMIP6 climate models can replicate the historical spatial distribution of CAOs and capture the decreasing frequency of CAOs for most of the globe. However, there are still large interannual discrepancies between the historically simulated and observed number of CAO days. An ensemble of historical simulations from different climate models was used to reduce errors in individual models. This ensemble approach was applied to each SSP to provide the best estimate of changes in CAOs for 10 regions across the globe.

Future simulations of CAOs show the decreasing frequency of CAOs in most regions will continue over the coming decades and in most cases disappear by 2054, however, there are several instances where CAOs increase. CAOs in the North Atlantic (R4) are shown to increase in frequency between 2035 and 2050 which may be a response to the continued weakening of the AMOC (Gent, 2018). The frequency of CAOs in North America and Eurasia may also remain consistent over the next 10 to 20 years before decreasing to approximately zero annual CAO days by 2054. In several regions, climate models incorrectly continued a decreasing trend in CAOs from the historical simulation through the onset of the future simulations. This was true in Europe (R6), Siberia (R5), Alaska (R3), and to a lesser extent the eastern United States (R1) where the frequency of CAOs increased in the last decade. While this observed increase is not likely to persist in a warming climate, the underestimated frequency of CAOs at the beginning of the future simulations may have impacted the projected number of CAOs through 2054 . Errors in historical CAO simulations may indicate inaccuracies in future projections, thus projections of CAOs in the North Atlantic and Alaska should be interpreted with caution.

Outside of the North Atlantic, all three SSPs showed the largest changes in CAO frequency to be on land as opposed to the oceans. This is to be expected as the higher heat capacity of water causes the oceans to change more slowly than land (Rathore et al., 2020). Though SSP126 generally favors a higher frequency of CAOs through 2054, SSP245 and SSP585 have a higher frequency of CAOs in the near-term for several regions. This suggests interannual fluctuations in CAO frequency may be more dependent on regional climate forcing than systematic warming. Nonetheless, the decrease in the frequency of CAOs is evident in even the most conservative scenario (SSP126) for every region.

Because this study uses the 1981 - 2010 climate normal period in the calculation of CAOs, adjusting this period would certainly impact the frequency of CAOs in future simulations. Though infrastructure often depends on absolute temperature thresholds, humans have been shown to be negatively impacted by relative extremes (Sheridan et al., 2019). It would be worthwhile for future studies to explore projected 
changes in the frequency of CAOs with a dynamic 30-year climate normal period as opposed to a single static 30-year period.

\section{Declarations}

\section{Conflict of Interest:}

There are no conflicts of interest

Funding: NA

Data availability: All data used in this study is publicly available. The data that supports these findings are available at the Mendeley Data repository (Smith, Erik (2020), "Cold Air Outbreaks", Mendeley Data, v1. http://dx.doi.org/10.17632/mtwfvcry5z.1). Climate model data was accessed via the Earth System Grid Federation (CMIP6-DKRZ Data Search | CMIP6-DKRZ | ESGF-CoG).

Materials availability: See Data Availability Statement

Code availability: NA

\section{Author Contributions:}

Erik Smith: Lead Author and Researcher

Scott Sheridan: Advisor

- Conflict of Interest / Competing interests: None

Additional declarations for articles that report the results of studies involving humans and/or animals:

- Ethics approval: NA

- Consent to participate: NA

- Consent for publication: NA

\section{Acknowledgements and Data Availability}

The data that supports these findings are available at the Mendeley Data repository (Smith, Erik (2020), "Cold Air Outbreaks", Mendeley Data, v1. http://dx.doi.org/10.17632/mtwfvcvy5z.1). This repository contains a dataset with the dates of the individual CAOs as an .xlsx file. A larger dataset is also available as a mat file and requires a MATLAB license to access. These datasets were created using ERA5 and CMIP6 climate model output near-surface temperature data. ERA5 near-surface temperature data is available from the European Center for Medium-Range Weather Forecasts (ECMWF) via the Copernicus Climate Change Service at https://cds.climate.copernicus.eu/cdsapp\#!/dataset/reanalysis-era5-single- 
levels. Climate model output from the CMIP6 archive is publicly available from the Earth System Grid Federation (ESGF; https://esgf-node.IInl.gov/search/cmip6/).

\section{References}

1. Almazroui, M., Saeed, F., Saeed, S., Nazrul Islam, M., Ismail, M., Klutse, N. A. B., \& Siddiqui, M. H. (2020). Projected Change in Temperature and Precipitation Over Africa from CMIP6. Earth Systems and Environment, 4(3), 455-475. https://doi.org/10.1007/s41748-020-00161-x

2. Ayarzagüena, B., \& Screen, J. A. (2016). Future Arctic sea ice loss reduces severity of cold air outbreaks in midlatitudes: Sea Ice Loss and Midlatitude CAOs. Geophysical Research Letters, 43(6), 2801-2809. https://doi.org/10.1002/2016GL068092

3. Bauer, N., Calvin, K., Emmerling, J., Fricko, O., Fujimori, S., Hilaire, J., Eom, J., Krey, V., Kriegler, E., Mouratiadou, I., Sytze de Boer, H., van den Berg, M., Carrara, S., Daioglou, V., Drouet, L., Edmonds, J. E., Gernaat, D., Havlik, P., Johnson, N., ... van Vuuren, D. P. (2017). Shared Socio-Economic Pathways of the Energy Sector - Quantifying the Narratives. Global Environmental Change, 42, 316-330. https://doi.org/10.1016/j.gloenvcha.2016.07.006

4. Bell, J. E., Brown, C. L., Conlon, K., Herring, S., Kunkel, K. E., Lawrimore, J., Luber, G., Schreck, C., Smith, A., \& Uejio, C. (2018). Changes in extreme events and the potential impacts on human health. Journal of the Air \& Waste Management Association, 68(4), 265-287.

https://doi.org/10.1080/10962247.2017.1401017

5. Cohen, J. L., Furtado, J. C., Barlow, M. A., Alexeev, V. A., \& Cherry, J. E. (2012). Arctic warming, increasing snow cover and widespread boreal winter cooling. Environmental Research Letters, 7(1), 014007. https://doi.org/10.1088/1748-9326/7/1/014007

6. Cohen, J., Pfeiffer, K., \& Francis, J. A. (2018). Warm Arctic episodes linked with increased frequency of extreme winter weather in the United States. Nature Communications, 9(1). https://doi.org/10.1038/s41467-018-02992-9

7. Collins, S. N., James, R. S., Ray, P., Chen, K., Lassman, A., \& Brownlee, J. (2013). Grids in Numerical Weather and Climate Models. Climate Change and Regional/Local Responses. https://doi.org/10.5772/55922

8. Danabasoglu, G., Lamarque, J.-F., Bacmeister, J., Bailey, D. A., DuVivier, A. K., Edwards, J., Emmons, L. K., Fasullo, J., Garcia, R., Gettelman, A., Hannay, C., Holland, M. M., Large, W. G., Lauritzen, P. H., Lawrence, D. M., Lenaerts, J. T. M., Lindsay, K., Lipscomb, W. H., Mills, M. J., ... Strand, W. G. (2020). The Community Earth System Model Version 2 (CESM2). Journal of Advances in Modeling Earth Systems, 12(2), e2019MS001916. https://doi.org/10.1029/2019MS001916

9. Davis, S. J., Lewis, N. S., Shaner, M., Aggarwal, S., Arent, D., Azevedo, I. L., Benson, S. M., Bradley, T., Brouwer, J., Chiang, Y.-M., Clack, C. T. M., Cohen, A., Doig, S., Edmonds, J., Fennell, P., Field, C. B., Hannegan, B., Hodge, B.-M., Hoffert, M. I., ... Caldeira, K. (2018). Net-zero emissions energy systems. Science, 360(6396). https://doi.org/10.1126/science.aas9793 
10. Dee, D. P., Uppala, S. M., Simmons, A. J., Berrisford, P., Poli, P., Kobayashi, S., Andrae, U., Balmaseda, M. A., Balsamo, G., Bauer, P., Bechtold, P., Beljaars, A. C. M., van de Berg, L., Bidlot, J., Bormann, N., Delsol, C., Dragani, R., Fuentes, M., Geer, A. J., ... Vitart, F. (2011). The ERA-Interim reanalysis: Configuration and performance of the data assimilation system. Quarterly Journal of the Royal Meteorological Society, 137(656), 553-597. https://doi.org/10.1002/qj.828

11. Edwards, P. N. (2011). History of climate modeling. WIREs Climate Change, 2(1), 128-139. https://doi.org/10.1002/wcc.95

12. Ehret, U., Zehe, E., Wulfmeyer, V., Warrach-Sagi, K., \& Liebert, J. (2012). HESS Opinions. Hydrology and Earth System Sciences Discussions, 9, 5355-5387. https://doi.org/10.5194/hessd-9-5355-2012

13. Eyring, V., Bony, S., Meehl, G. A., Senior, C. A., Stevens, B., Stouffer, R. J., \& Taylor, K. E. (2016). Overview of the Coupled Model Intercomparison Project Phase 6 (CMIP6) experimental design and organization. Geoscientific Model Development, 9(5), 1937-1958. https://doi.org/10.5194/gmd-91937-2016

14. Flato, G. M. (2011). Earth system models: An overview. WIREs Climate Change, 2(6), 783-800. https://doi.org/10.1002/wcc.148

15. Friedrich, T., Timmermann, A., Tigchelaar, M., Elison Timm, O., \& Ganopolski, A. (2016). Nonlinear climate sensitivity and its implications for future greenhouse warming. Science Advances, 2(11), e1501923. https://doi.org/10.1126/sciadv.1501923

16. Gent, P. R. (2018). A commentary on the Atlantic meridional overturning circulation stability in climate models. Ocean Modelling, 122, 57-66. https://doi.org/10.1016/j.ocemod.2017.12.006

17. Gutjahr, O., Putrasahan, D., Lohmann, K., Jungclaus, J. H., von Storch, J.-S., Brüggemann, N., Haak, H., \& Stössel, A. (2019). Max Planck Institute Earth System Model (MPI-ESM1.2) for the High-Resolution Model Intercomparison Project (HighResMIP). Geoscientific Model Development, 12(7), 3241-3281. https://doi.org/10.5194/gmd-12-3241-2019

18. Hu, A., Meehl, G. A., Han, W., Yin, J., Wu, B., \& Kimoto, M. (2013). Influence of Continental Ice Retreat on Future Global Climate. Journal of Climate, 26(10), 3087-3111. https://doi.org/10.1175/JCLI-D12-00102.1

19. Jeuken, A. B. M., Siegmund, P. C., Heijboer, L. C., Feichter, J., \& Bengtsson, L. (1996). On the potential of assimilating meteorological analyses in a global climate model for the purpose of model validation. Journal of Geophysical Research: Atmospheres, 101(D12), 16939-16950. https://doi.org/10.1029/96JD01218

20. Jones, G. S., Stott, P. A., \& Christidis, N. (2013). Attribution of observed historical near-surface temperature variations to anthropogenic and natural causes using CMIP5 simulations. Journal of Geophysical Research: Atmospheres, 118(10), 4001-4024. https://doi.org/10.1002/jgrd.50239

21. Kalnay, E. (2003). Atmospheric Modeling, Data Assimilation and Predictability. Cambridge University Press.

22. Kim, W. M., Yeager, S., Chang, P., \& Danabasoglu, G. (2018). Low-Frequency North Atlantic Climate Variability in the Community Earth System Model Large Ensemble. Journal of Climate, 31(2), 787- 
813. https://doi.org/10.1175/JCLI-D-17-0193.1

23. Kim, Y., \& Lee, S. (2019). Trends of extreme cold events in the central regions of Korea and their influence on the heating energy demand. Weather and Climate Extremes, 24, 100199. https://doi.org/10.1016/j.wace.2019.100199

24. Klinger, C., Landeg, O., \& Murray, V. (2014). Power Outages, Extreme Events and Health: A Systematic Review of the Literature from 2011-2012. PLoS Currents, 6. https://doi.org/10.1371/currents.dis.04eb1dc5e73dd1377e05a10e9edde673

25. Kolstad, E. W., \& Bracegirdle, T. J. (2008). Marine cold-air outbreaks in the future: An assessment of IPCC AR4 model results for the Northern Hemisphere. Climate Dynamics, 30(7), 871-885. https://doi.org/10.1007/s00382-007-0331-0

26. Kumar, S., Merwade, V., Kinter, J. L., \& Niyogi, D. (2013). Evaluation of Temperature and Precipitation Trends and Long-Term Persistence in CMIP5 Twentieth-Century Climate Simulations. Journal of Climate, 26(12), 4168-4185. https:// doi.org/10.1175/JCLI-D-12-00259.1

27. Labe, Z., Peings, Y., \& Magnusdottir, G. (2020). Warm Arctic, Cold Siberia Pattern: Role of Full Arctic Amplification Versus Sea Ice Loss Alone. Geophysical Research Letters, 47(17), e2020GL088583. https://doi.org/10.1029/2020GL088583

28. Lesk, C., Rowhani, P., \& Ramankutty, N. (2016). Influence of extreme weather disasters on global crop production. Nature, 529(7584), 84-87. https://doi.org/10.1038/nature16467

29. Liu, Han-Li, Bardeen, C. G., Foster, B. T., Lauritzen, P., Liu, J., Lu, G., Marsh, D. R., Maute, A., Mclnerney, J. M., Pedatella, N. M., Qian, L., Richmond, A. D., Roble, R. G., Solomon, S. C., Vitt, F. M., \& Wang, W. (2018). Development and Validation of the Whole Atmosphere Community Climate Model With Thermosphere and Ionosphere Extension (WACCM-X 2.0). Journal of Advances in Modeling Earth Systems, 10(2), 381-402. https://doi.org/10.1002/2017MS001232

30. Liu, H.-L., Foster, B. T., Hagan, M. E., Mclnerney, J. M., Maute, A., Qian, L., Richmond, A. D., Roble, R. G., Solomon, S. C., Garcia, R. R., Kinnison, D., Marsh, D. R., Smith, A. K., Richter, J., Sassi, F., \& Oberheide, J. (2010). Thermosphere extension of the Whole Atmosphere Community Climate Model. Journal of Geophysical Research: Space Physics, 115(A12). https://doi.org/10.1029/2010JA015586

31. Liu, X., Shen, B., Price, L., Hasanbeigi, A., Lu, H., Yu, C., \& Fu, G. (2019). A review of international practices for energy efficiency and carbon emissions reduction and lessons learned for China. WIRES Energy and Environment, 8(5), e342. https://doi.org/10.1002/wene.342

32. Luca, A. D., Pitman, A. J., \& de Elía, R. (2020). Decomposing Temperature Extremes Errors in CMIP5 and CMIP6 Models. Geophysical Research Letters, 47(14), e2020GL088031. https://doi.org/10.1029/2020GL088031

33. Maraun, D. (2016). Bias Correcting Climate Change Simulations-A Critical Review. Current Climate Change Reports, 2(4), 211-220. https://doi.org/10.1007/s40641-016-0050-x

34. Meehl, G. A., Arblaster, J. M., Bates, S., Richter, J. H., Tebaldi, C., Gettelman, A., Medeiros, B., Bacmeister, J., DeRepentigny, P., Rosenbloom, N., Shields, C., Hu, A., Teng, H., Mills, M. J., \& Strand, G. 
(2020). Characteristics of Future Warmer Base States in CESM2. Earth and Space Science, 7(9), e2020EA001296. https://doi.org/10.1029/2020EA001296

35. O’Neill, B. C., Kriegler, E., Riahi, K., Ebi, K. L., Hallegatte, S., Carter, T. R., Mathur, R., \& van Vuuren, D. P. (2014). A new scenario framework for climate change research: The concept of shared socioeconomic pathways. Climatic Change, 122(3), 387-400. https://doi.org/10.1007/s10584-0130905-2

36. O’Neill, B. C., Tebaldi, C., Van Vuuren, D. P., Eyring, V., Friedlingstein, P., Hurtt, G., Knutti, R., Kriegler, E., Lamarque, J. F., Lowe, J., Meehl, G. A., Moss, R., Riahi, K., \& Sanderson, B. M. (2016). The Scenario Model Intercomparison Project (ScenarioMIP) for CMIP6. https://doi.org/10.5194/gmd-9-3461-2016

37. Polkova, I., Köhl, A., \& Stammer, D. (2019). Climate-mode initialization for decadal climate predictions. Climate Dynamics, 53(11), 7097-7111. https://doi.org/10.1007/s00382-019-04975-y

38. Raäisaänen, J. (2007). How reliable are climate models? Tellus A: Dynamic Meteorology and Oceanography, 59(1), 2-29. https://doi.org/10.1111/j.1600-0870.2006.00211.x

39. Randall, D. A., Wood, R. A., Bony, S., Colman, R., Fichefet, T., Fyfe, J., Kattsov, V., Pitman, A., Shukla, J., Srinivasan, J., Stouffer, R. J., Sumi, A., Taylor, K. E., AchutaRao, K., Allan, R., Berger, A., Blatter, H., Bonfils, C., Boone, A., ... McAvaney, B. (n.d.). Climate Models and Their Evaluation. 74.

40. Rathore, S., Bindoff, N. L., Phillips, H. E., \& Feng, M. (2020). Recent hemispheric asymmetry in global ocean warming induced by climate change and internal variability. Nature Communications, 11(1), 2008. https://doi.org/10.1038/s41467-020-15754-3

41. Richardson, L. F. (2007). Weather Prediction by Numerical Process. Cambridge University Press.

42. Schewe, J., Gosling, S. N., Reyer, C., Zhao, F., Ciais, P., Elliott, J., Francois, L., Huber, V., Lotze, H. K., Seneviratne, S. I., van Vliet, M. T. H., Vautard, R., Wada, Y., Breuer, L., Büchner, M., Carozza, D. A., Chang, J., Coll, M., Deryng, D., ... Warszawski, L. (2019). State-of-the-art global models underestimate impacts from climate extremes. Nature Communications, 10(1), 1005. https://doi.org/10.1038/s41467-019-08745-6

43. Sheridan, S. C., Lee, C. C., \& Allen, M. J. (2019). The Mortality Response to Absolute and Relative Temperature Extremes. International Journal of Environmental Research and Public Health, 16(9), 1493. https://doi.org/10.3390/ijerph16091493

44. Smith, D. M., Scaife, A. A., Eade, R., Athanasiadis, P., Bellucci, A., Bethke, I., Bilbao, R., Borchert, L. F., Caron, L.-P., Counillon, F., Danabasoglu, G., Delworth, T., Doblas-Reyes, F. J., Dunstone, N. J., EstellaPerez, V., Flavoni, S., Hermanson, L., Keenlyside, N., Kharin, V., ... Zhang, L. (2020). North Atlantic climate far more predictable than models imply. Nature, 583(7818), 796-800. https://doi.org/10.1038/s41586-020-2525-0

45. Smith, E. T., \& Sheridan, S. C. (2019). The influence of extreme cold events on mortality in the United States. Science of The Total Environment, 647, 342-351.

https://doi.org/10.1016/j.scitotenv.2018.07.466

46. Smith, E. T., \& Sheridan, S. C. (2020). Where Do Cold Air Outbreaks Occur, and How Have They Changed Over Time? Geophysical Research Letters, 47(13), e2020GL086983. 
https://doi.org/10.1029/2020GL086983

47. Smith, E.T. (2020), “Cold Air Outbreaks”, Mendeley Data, V1, doi: 10.17632/mtwfvcvy5z.1

48. Swart, N. C., Cole, J. N. S., Kharin, V. V., Lazare, M., Scinocca, J. F., Gillett, N. P., Anstey, J., Arora, V., Christian, J. R., Hanna, S., Jiao, Y., Lee, W. G., Majaess, F., Saenko, O. A., Seiler, C., Seinen, C., Shao, A., Sigmond, M., Solheim, L., ... Winter, B. (2019). The Canadian Earth System Model version 5 (CanESM5.0.3). Geoscientific Model Development, 12(11), 4823-4873.

https://doi.org/10.5194/gmd-12-4823-2019

49. Tebaldi, C., Debeire, K., Eyring, V., Fischer, E., Fyfe, J., Friedlingstein, P., Knutti, R., Lowe, J., O’Neill, B., Sanderson, B., van Vuuren, D., Riahi, K., Meinshausen, M., Nicholls, Z., Hurtt, G., Kriegler, E., Lamarque, J.-F., Meehl, G., Moss, R., ... Ziehn, T. (2020). Climate model projections from the Scenario Model Intercomparison Project (ScenarioMIP) of CMIP6. Earth System Dynamics Discussions, 1-50. https://doi.org/10.5194/esd-2020-68

50. Tokarska, K. B., Stolpe, M. B., Sippel, S., Fischer, E. M., Smith, C. J., Lehner, F., \& Knutti, R. (2020). Past warming trend constrains future warming in CMIP6 models. Science Advances, 6(12), eaaz9549. https://doi.org/10.1126/sciadv.aaz9549

51. Vavrus, S., Walsh, J. E., Chapman, W. L., \& Portis, D. (2006). The behavior of extreme cold air outbreaks under greenhouse warming. International Journal of Climatology, 26(9), 1133-1147. https://doi.org/10.1002/joc.1301

52. Wang, T., Hamann, A., Spittlehouse, D., \& Carroll, C. (2016). Locally Downscaled and Spatially Customizable Climate Data for Historical and Future Periods for North America. PLOS ONE, 11(6), e0156720. https://doi.org/10.1371/journal.pone.0156720

53. Wilks, D. S. (2016). "The Stippling Shows Statistically Significant Grid Points": How Research Results are Routinely Overstated and Overinterpreted, and What to Do about It. Bulletin of the American Meteorological Society, 97(12), 2263-2273. https://doi.org/10.1175/BAMS-D-15-00267.1

54. Yukimoto, S., Kawai, H., Koshiro, T., Oshima, N., Yoshida, K., Urakawa, S., Tsujino, H., Deushi, M., Tanaka, T., Hosaka, M., Yabu, S., Yoshimura, H., Shindo, E., Mizuta, R., Obata, A., Adachi, Y., \& Ishii, M. (2019). The Meteorological Research Institute Earth System Model Version 2.0, MRI-ESM2.0: Description and Basic Evaluation of the Physical Component. Journal of the Meteorological Society of Japan. Ser. II, 97(5), 931-965. https://doi.org/10.2151/jmsj.2019-051

55. Yun, W.-T., Stefanova, L., \& Krishnamurti, T. (2003). Improvement of the Multimodel Superensemble Technique for Seasonal Forecasts. Journal of Climate, 16, 3834-3840. https://doi.org/10.1175/1520-0442(2003)016<3834:IOTMST>2.0.CO;2

56. Zahn, M., \& von Storch, H. (2010). Decreased frequency of North Atlantic polar lows associated with future climate warming. Nature, 467(7313), 309-312. https://doi.org/10.1038/nature09388

57. Zhang, R., Sutton, R., Danabasoglu, G., Kwon, Y.-O., Marsh, R., Yeager, S. G., Amrhein, D. E., \& Little, C. M. (2019). A Review of the Role of the Atlantic Meridional Overturning Circulation in Atlantic Multidecadal Variability and Associated Climate Impacts. Reviews of Geophysics, 57(2), 316-375. https://doi.org/10.1029/2019RG000644 


\section{Tables}

Table 2 is not available with this version.

\section{Figures}

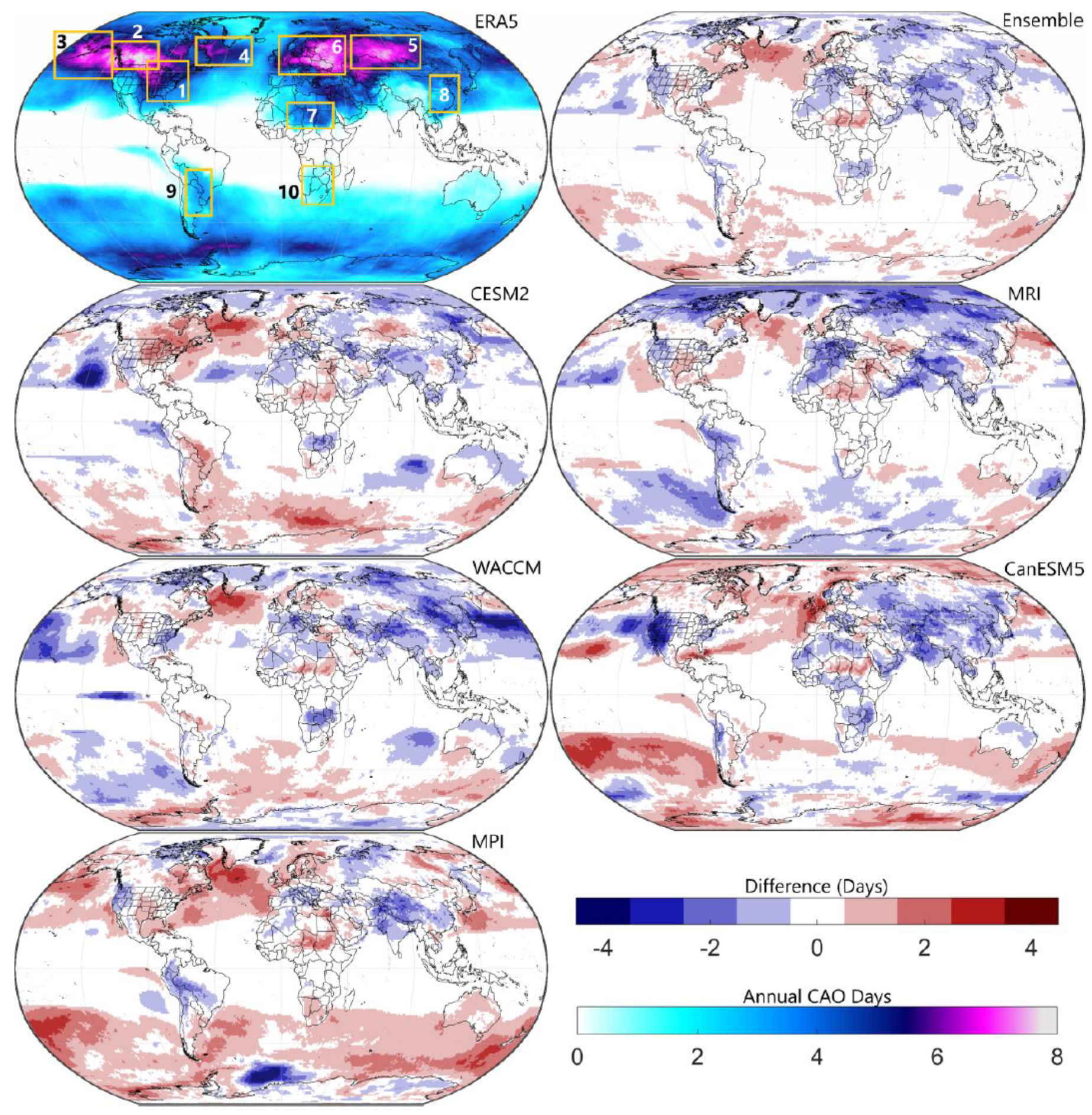

Figure 1 
Observed annual cold air outbreak (CAO) days from 1979 - 2014 (ERA5) and the difference between the simulated annual CAO days for the five CMIP6 climate models (CESM2, WACCM, MPI, MRI, and CanESM5) and the ensemble. Regions are denoted with bounding boxes in the ERA5 figure (Smith and Sheridan, 2020).

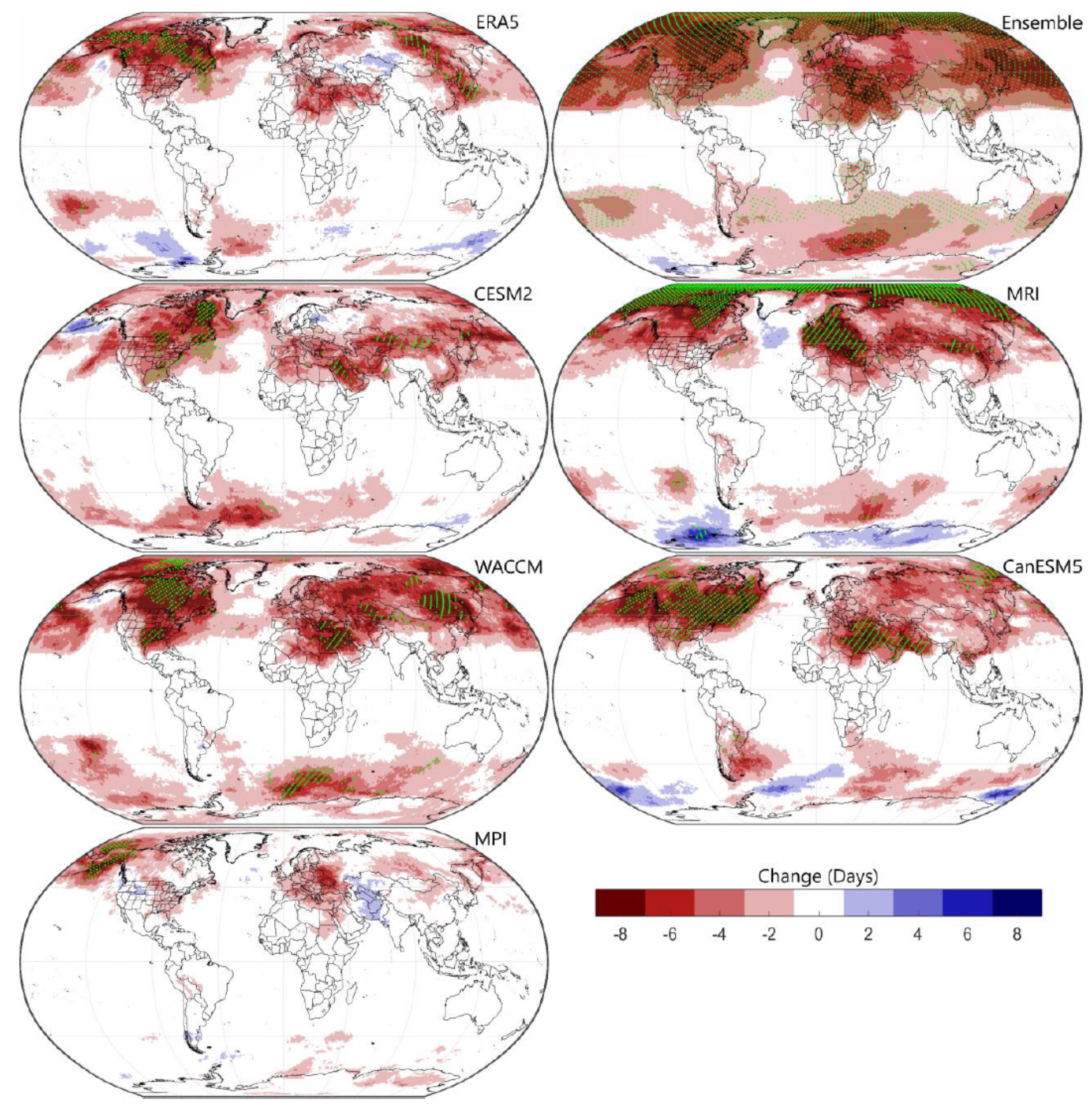

Figure 2

Change in the mean annual number of CAO days. For the observed trends (ERA5), every 5th significant grid point at the $a=0.05$ level is denoted with green dots. Size and spacing of Ensemble green dots are 
altered because of the number of dots.

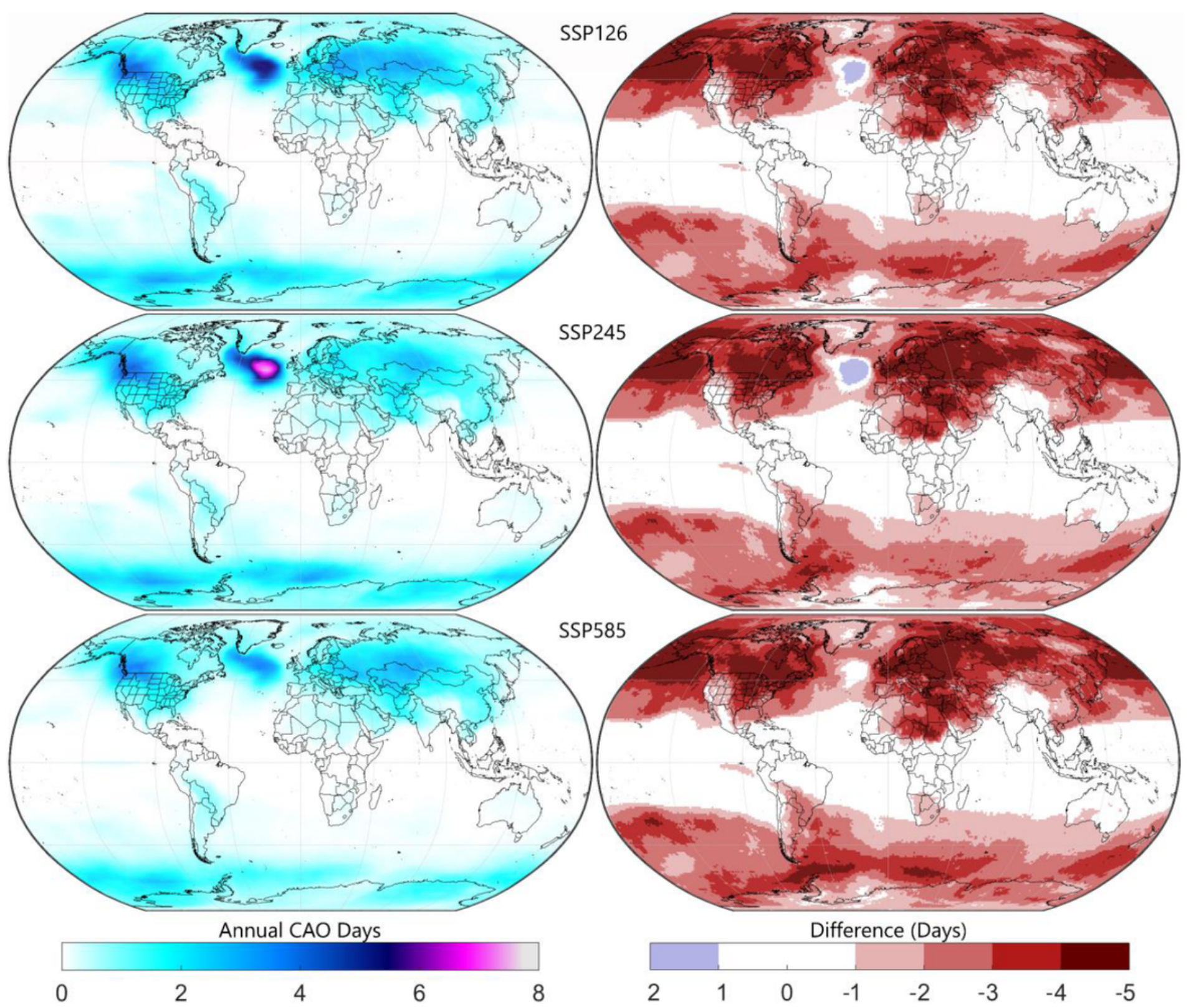

Figure 3

Left - ensemble of simulated annual CAO days from 2015 - 2054 for three future scenarios: SSP126, SSP245 and SSP585. Right - difference between each SSP and the mean annual number of CAO days from $1979-2014$. 


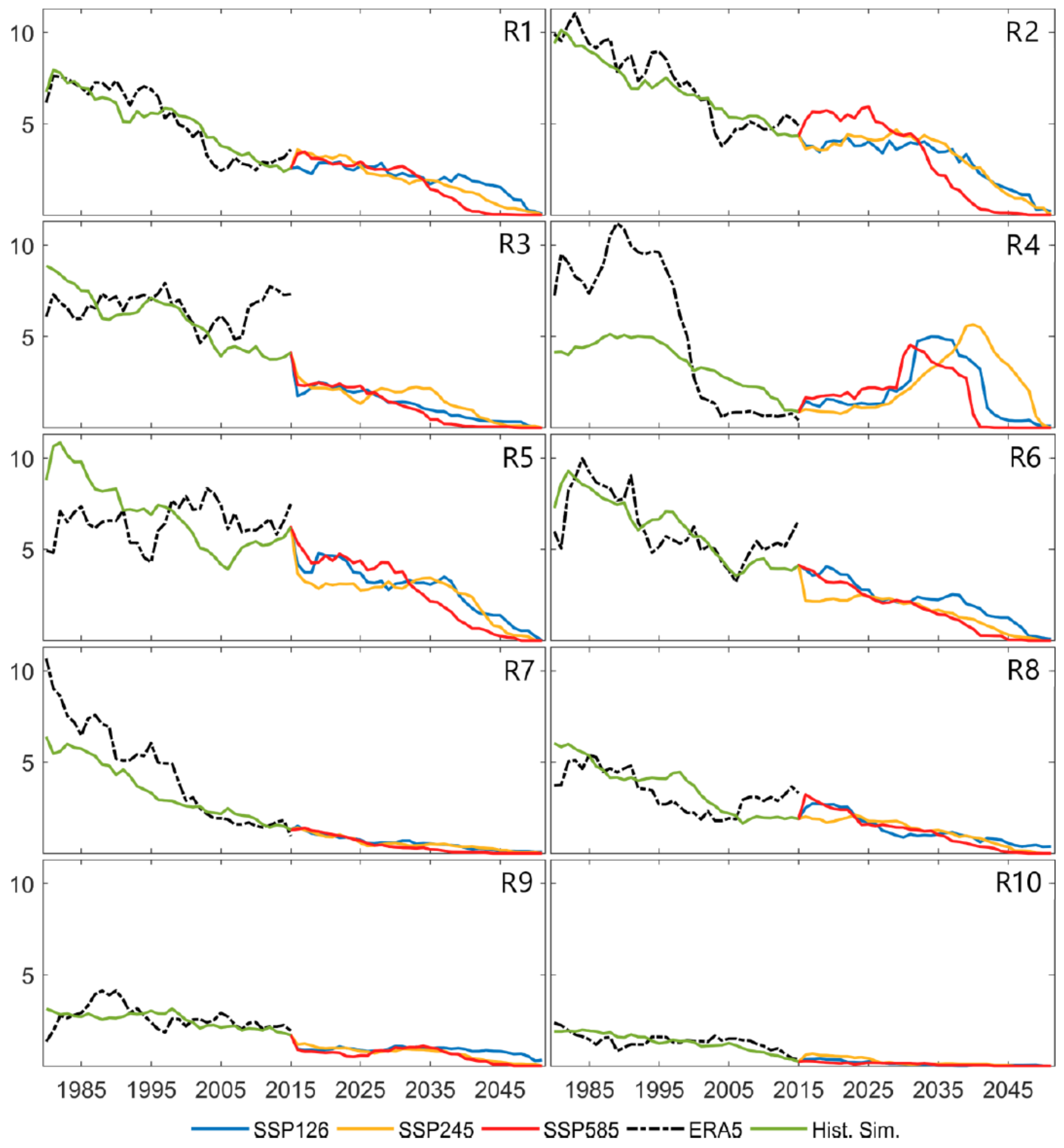

Figure 4

Smoothed time series of observed annual CAO days per region from the ERA5 (black), the simulated historical time series for the climate model ensemble (green) from 1979 - 2014, and the climate model ensemble projections of annual CAO days per region for each of the three SSP scenarios, SSP126 (blue), SSP245 (orange), and SSP585 (red), from 2015 - 2054. 


\section{Supplementary Files}

This is a list of supplementary files associated with this preprint. Click to download.

- Appendix.docx 